\title{
A Comparative Assessment of Disability Levels among Nigerian Outpatients with Schizophrenia and Type 2 Diabetes Mellitus
}

\author{
Maigari Yusufu Taru1,2*, Akinyemi Opeyemi Faith ${ }^{3}$, Lubuola Issa Bamidele ${ }^{4}$, \\ Tungchama Friday Philip1,2
}

${ }^{1}$ Department of Psychiatry, University of Jos, Jos, Nigeria

${ }^{2}$ Department of Psychiatry, Jos University Teaching Hospital, Jos, Nigeria

${ }^{3}$ Federal Medical Centre, Abeokuta, Nigeria

${ }^{4}$ Federal Neuropsychiatric Hospital, Kaduna, Nigeria

Email: ^Tmaigariyusufu@yahoo.com

How to cite this paper: Taru, M.Y., Faith, A.O., Bamidele, L.I. and Philip, T.F. (2022) A Comparative Assessment of Disability Levels among Nigerian Outpatients with Schizophrenia and Type 2 Diabetes Mellitus. Open Journal of Psychiatry, 12, 78-97. https://doi.org/10.4236/ojpsych.2022.121008

Received: August 14, 2021

Accepted: January 10, 2022

Published: January 13, 2022

Copyright $\odot 2022$ by author(s) and Scientific Research Publishing Inc. This work is licensed under the Creative Commons Attribution International License (CC BY 4.0).

http://creativecommons.org/licenses/by/4.0/

(c) (i) Open Access

\begin{abstract}
Background: Chronic illnesses are often associated with functional disability, thus compromising the ability to carry out everyday activities of daily living. The degree of disability depends on the severity and the type of illness experienced. Studies that compare the level of disability between people with chronic medical conditions and mental illnesses in North-Central Nigeria are scarce. This study aims to compare the disability levels between people with schizophrenia and Type 2 Diabetes Mellitus (T2DM) attending outpatient clinics at the Jos University Teaching Hospital, north-central Nigeria, and evaluate the factors associated with these conditions. Methods: It was a cross-sectional study with a total of 600 patients who were diagnosed with schizophrenia and T2DM, attending the Psychiatric and medical outpatient clinics of the Jos University Teaching Hospital, north-central Nigeria, between June 2017 and November 2017. The study assessed Psychotic and non-psychotic symptoms by applying the Brief Psychiatric Rating Scale (BPRS) among those with schizophrenia. We evaluated the level of disability by using World Health Organization Disability Assessment Schedule version 2.0 (WHODAS 2.00). Results: Disability was significantly higher among respondents with schizophrenia than those with T2DM. This difference occurred across all the domains except domain 2 (moving around). Marital status, living situation, occupation, and treatment adherence were significant common factors associated with disability in these conditions. In contrast, age, educational status, income level, and duration of illness were significantly
\end{abstract}


associated with disability among respondents with T2DM only. Conclusion: Disability and its associated factors among people with chronic diseases, if identified early and proper interventions instituted, disability can be avoided or minimized among people with chronic illnesses.

\section{Keywords}

Chronic Conditions, Disability, Comparative Assessment, WHODAS

\section{Introduction}

Chronic conditions are human health conditions or diseases that are persistent or otherwise long-lasting in their effects [1]. These conditions frequently cause functional disability, characterized by restriction or deterioration of an individual's expected functioning in a particular society, family, or social group [2]. Based on the World Health Organization report of 2020, about 15 percent of the world's population experience some form of disability, with the rate increase, in part due to aging populations and an increase in chronic health conditions [3]. Not only are the number of persons living with disabilities increasing, but also people with disabilities may experience adverse socioeconomic outcomes such as less education, poorer health outcomes, lower levels of employment, and higher poverty rates [4].

The degree of disability experienced by people with chronic conditions correlates with the conditions' type and the associated demographic and clinical factors [5]-[10]. However, certain chronic illnesses have been recognized as prominent causes of significant disability in the community. Cardiac diseases, arthritis, and chronic mental illness are among the most notable [11]. Mental illnesses account for nearly $31 \%$ of the world's disability [12], and schizophrenia is the most disabling mental illness [6]. Despite being a low prevalence disorder, schizophrenia ranked the 12th most disabling disorder among 310 diseases and injuries globally in 2016 [13]. Ertugrul \& Ulug (2002), using WHODAS II, demonstrated that life activities, participation in society, understanding and communicating with the world, and getting along with people were the domains with a high level of disability in individuals with schizophrenia [14]. Thus, if not minimized, the breadth of the resultant disability from schizophrenia could lead to enormous health care costs and economic losses.

On the other hand, Diabetes mellitus (DM) is a chronic medical condition characterized by defects in insulin secretion and or action, resulting in sustained high blood glucose levels [15]. There are two broad types of diabetes mellitus: type 1 diabetes and type 2 diabetes. This paper focuses on type 2 diabetes accounting for about $90 \%$ of all the cases [16]. Along the years of its course, the disease develops into complications, leading to various functional impairments and disabilities [17] [18] [19] [20], with a physical disability, in particular, being 
one of the most consistent. Disability in T2DM is associated with many poor outcomes, including loss of employment and productivity [21] [22] [23], yet the cost of treatment is high.

Previous studies have compared the degree of disability among patients with mental and physical illnesses [5] [7]; we could not identify any study that specifically compares the level of disability between individuals with schizophrenia and T2DM in north-central Nigeria. This study compares disability between patients with schizophrenia and T2DM attending outpatient clinics at the Jos University Teaching Hospital, north-central Nigeria. It also identifies the socio-demographic and clinical factors associated with the disability. Understanding the significant factors related to the disability is pivotal in minimizing or avoiding disability in these populations.

We hypothesized a significant difference in disability levels between patients with schizophrenia and T2DM, based on evidence from previous studies that found mental disorders to be more disabling than physical conditions [5] [7].

\section{Method and Materials}

\subsection{Design}

We conducted a cross-sectional study that compared disability levels between adults aged 18 years and above with a diagnosis of schizophrenia and T2DM who were stable and attending a clinic at the outpatients' Department of Psychiatry and Medicine of the Jos University Teaching Hospital north-central Nigeria between June and November 2017.

\subsection{Setting}

We conducted the study at the Psychiatric and Medical outpatient clinics of the Jos University Teaching Hospital, a federal government-owned tertiary hospital in north-central Nigeria, with a capacity of about 600 beds. It was initially a General Hospital, converted to a Teaching Hospital in 1977 to train medical students of the University of Jos. The department of psychiatry was established as a unit of the hospital in 1978. The hospital is a referral center for patients from the north-central, north-eastern, and north-western Nigeria, including Plateau, Bauchi, Nasarawa, Benue, Taraba, Kaduna, Adamawa states, and the federal capital territory.

The Department of Psychiatry operates at the old site, located at the heart of Jos city, the capital of Plateau State. It is about $13 \mathrm{~km}$ from the permanent site. The Psychiatric outpatient clinic, which includes: General Adult Psychiatry clinic, Psychogeriatric clinic, Child \& Adolescent Clinic, Emergency, and Consultation-Liaison clinic, holds five times a week from Monday to Friday. Available statistics from the record department showed an average of 30 - 50 patients per clinic day, out of which one in four of the patients seen were likely to have a diagnosis of schizophrenia. 
The comparative group was drawn from the Endocrine Unit of the Medical outpatient clinic, JUTH, located at the permanent site of the hospital at Lamingo. The Endocrine clinic runs twice weekly, with an average of 15 - 20 patients diagnosed with Type 2DM on follow-up visits per clinic day.

\subsection{Participants \& Sampling}

Adults aged 18 years and above with a diagnosis of Schizophrenia and T2DM as confirmed by a Consultant Psychiatrist according to the International Classification of Diseases (ICD-10) [24] and Consultant Endocrinologist according to WHO diagnostic criteria [25] who at the time of this study were clinically stable, with the last hospital admission at least six months or more before the date of assessment, were eligible for the study. We excluded subjects who declined consent, had a BPRS score of $\geq 10$, fasting blood glucose of $\geq 10 / \mathrm{mml} / \mathrm{L}$, had more than one principal diagnosis, and had moderate to a severe disabling general medical condition. Furthermore, were excluded participants with clear evidence that their illness had been on for less than one year from the study.

We first stratified the participants into two groups based on diagnosis and clinic location and employed a systematic random sampling technique to select eligible respondents from each group. The tradition in psychiatric and medical outpatient clinics is that folders are retrieved and arranged serially based on patients' arrival. Thus, the folders for the patients diagnosed with the conditions under study were selected and assigned a serial number in a sequence (sampling frame for the day $=\mathrm{N}$ ). We determined the number of participants recruited per clinic day $(n=9)$ during our pilot study.

The sampling procedure is as follows:

Sampling interval $(K)=N / n$.

$\mathrm{N}$ = sampling frame (number of patients seen per clinic day.

$\mathrm{n}=$ daily sample size (number of subjects to be recruited daily) as determined during the pilot study $=9$.

In psychiatric clinic, about 30 - 50 patients, out of which 1 in $4(8-13)$, an average of 20 are likely to have a diagnosis of schizophrenia $=\mathrm{N}$.

Thus, $\mathrm{K}=20 / 9=2$.

For patients with T2DM $15-20$ with an average of 18 seen per clinic day $=\mathrm{N}$.

Thus, $\mathrm{K}=20 / 9=2$.

The first participant was chosen by randomly selecting 1 or 2 (simple balloting). Subsequently, every second participant that fulfilled the inclusion criteria was selected.

We made a notation on the selected folders to prevent subsequent selection of the same patients. This recruitment process was done twice weekly in both clinics, with an average of 15 - 18 patients assessed per week in each clinic over six months, and we obtained our desired sample sizes.

We used the formula for the comparison of two groups to calculate our sample size below [26]. 


$$
n=\frac{[P 1(1-P 1)+P 2(1-P 2)] \times C}{(P 1-P 2)^{2}}
$$

$n=$ calculated sample size per group.

$C=$ Standard value for the corresponding levels of $\alpha$ and $\beta$ set at 7.85 (at 95\% $\mathrm{CI}$ and $80 \%$ power).

$P 1=$ Prevalence of disability in Schizophrenia among adults based on previous study $=41 \%[27]$.

$P 2=$ Average rate of disability among adults with diabetes between 1997-2011 = $29 \%[28]$.

Thus,

$$
\begin{aligned}
& n=\frac{[0.41(1-0.41)+0.29(1-0.29)] \times 7.85}{(0.41-0.29)^{2}} \\
& n=\frac{[(0.41 \times 0.59)+(0.3 \times 0.7)] \times 7.85}{0.12^{2}} \\
& n=\frac{(0.2419+0.2059) \times 7.85}{0.0144} \\
& n=\frac{0.4478 \times 7.85}{0.0144} \\
& n=244
\end{aligned}
$$

$n=244+24$ (considering $10 \%$ dropout or attrition $)=268$ which was rounded up to 300 .

Thus, the sample size was 300 subjects in each group. That means a total of 600 study subjects were required.

\subsection{Data Collection}

Six researchers who were fluent in both English and Hausa languages collected the data using the survey instruments. The researchers were, first of all, taught how to apply the tools by a senior colleague, who is a Consultant Psychiatrist, and he is conversant with the use of the survey instruments. After that, we carried out a pilot study on $10 \%$ of each sample size (30 of each group), fulfilling the inclusion criteria who agreed to be interviewed but did not form part of the sample under investigation (through a systematic random selection, with an interval of 2). The pilot study revealed that 9 participants could be recruited from each group daily. The pilot study also assessed the survey instruments' cultural applicability, administration time and determined and addressed any dilemma that could hamper the smooth running of the proper survey.

In the main study, we approached the participants in Psychiatric and Medical outpatient clinics through a systematic sampling of their folders based on retrieval order. Those Selected had their process of clinic review enhanced before they were invited to a cubicle for data collection, ensuring that they had enough privacy. Participants, who were literate enough, filled out the questionnaires in 
the presence of the researchers. At the same time, we used Hausa versions of the instruments to collect data from those who could not speak the English language.

Participants were administered the first questionnaire, the socio-demographic questionnaire, a semi-structured questionnaire designed explicitly by the researchers. The questionnaire sought socio-demographic information (age, gender, educational level, marital status, occupation, living condition, income) and clinical characteristics (duration of illness and adherence to treatment). The administration of the Brief Psychiatric Rating Scale (BPRS) follows this for those with schizophrenia. The BPRS is a widely used semi-structured instrument for assessing psychotic and non-psychotic symptoms in major Psychiatric illnesses, especially schizophrenia [29]. This instrument is valuable for documenting treatment efficacy in patients who have moderate to severe disease. The items from the BPRS form part of the diagnostic criteria for schizophrenia. Its score ranges from 1 (not present) to 7 (extremely severe) and 0 (not assessed). This instrument has been used in Nigeria to classify psychopathology into no or less prominent (relatively stable) and apparent psychopathology [30] [31] [32]. Thus, respondents who scored ten and above (prominent psychotic symptoms) were excluded from the study and replaced by eligible subjects.

Disability was assessed as the dependant variable using World Health Organization Disability Assessment Schedule version 2.0 (WHODAS 2.00). The WHODAS 2.0 is a comprehensive tool that assesses disability within the last 30 days. It emphasizes difficulties in the six domains of cognition, mobility, self-care, getting along with people, life activities, and participation, including work-related disability. The instrument has good validity, internal consistency, robust factor structure $(0.91-0.99)$, and overall inter-rater reliability of 0.9882 [33]. The tool has been successfully used in Nigeria [34] [35]. We used the 36-item interviewer-administered version in this study due to its relevance in populations with low literacy. Simple scoring involves assigning values $(0=$ none, $1=$ mild, $2=$ moderate, $3=$ severe, and $4=$ extreme), summing recoded item scores in each domain, and converting the summary score into a metric range. In this study, we used the Andrews et al. Scorings [36]. Individuals with a summary score of $\leq 9$ were assigned a low level of disability and $\geq \mathrm{t} 10$ as having a high level of disability.

The questionnaires were designed in English. They were translated to Hausa and back to English to maintain their consistency.

\subsection{Ethical Considerations}

We first obtained ethical clearance from the Health Research Ethical Committee of the Jos University Teaching Hospital. We also sought Permission from the Heads of Departments of Psychiatry and Internal Medicine. We received informed consent from the study participants after explaining the aim and objectives of the study to them, and their confidentiality was assured. It was also clear 
to them that the interviews were entirely voluntary; hence, they can withdraw at any stage if they wish, without any negative implications on their treatments. We put this in writing, and those who agreed to participate in the study were required to sign or thumbprint as appropriate. Participants identified with a high level of disability had their findings discussed with the managing consultant to consider integrated rehabilitative care.

\subsection{Data Analysis}

The Statistical Package for Social Sciences version 20 (SPSS-20) Software package analyzed the data. The results were presented using simple descriptive analysis. T-test was used to compare mean values of numerical variables, and a chi-square test was used to investigate the difference between categorical variables and their associations. Values of $\mathrm{P}<0.05$ were considered statistically significant [37].

\section{Results}

\subsection{Characteristics of Samples}

Respondents with T2MD were older, with 239 of them being at least 50 years, as against a total of 54 of the respondents with schizophrenia that were at least 50 years. The majority of 313 respondents were males, comprising $55.3 \%$ with schizophrenia and $44.7 \%$ with Type2DM. A high proportion, $72.3 \%$, and $54.0 \%$, of the respondents with schizophrenia, lived with their parents and spouses against $21.7 \%$ and $54.0 \%$ of those with Type2DM living with their parents and spouses. Only 69 of all respondents had no formal education. The rest had formal education, out of which $92.3 \%$ and $74.3 \%$ of the respondents with schizophrenia and Type2DM had at least a secondary level of education.

For marital status, $30.0 \%$ versus $72.3 \%$ of the respondents with schizophrenia versus Type2DM were married, while $51.7 \%$ and $6 \%$ of those with schizophrenia and Type2DM were never married before.

Less than half, $42 \%$ of the respondents with schizophrenia were employed and, 56\% of those with Type2DM were employed. While 169 and 97 of the respondents with schizophrenia and Type2DM had no stable monthly income, 131 as against 203 of the respondents with schizophrenia and Type2DM had a regular monthly income of at least N20,000.00.

The majority, $77 \%$ and $83 \%$ of the respondents with schizophrenia and T2DM have been having the illness for at least five years during the study, and 60\% and $79.7 \%$ of those with schizophrenia and Type2DM had been compliant with their treatment. The details of the sample socio-demographic and clinical characteristics are provided in Table 1.

\subsection{Disability among Participants with Schizophrenia and Type2DM}

Respondents with schizophrenia are more likely than those with Type2DM to 
Table 1. Socio-demographic characteristics, duration of illness, and adherence to treatment of participants with schizophrenia and Type2DM.

\begin{tabular}{|c|c|c|c|c|c|c|c|}
\hline \multirow{2}{*}{ Variables } & & \multirow{2}{*}{$\begin{array}{l}\text { Schizophrenia } \\
\text { n (\%) }\end{array}$} & \multirow{2}{*}{$\begin{array}{c}\text { Type2DM } \\
\text { n (\%) }\end{array}$} & \multirow{2}{*}{$\begin{array}{l}\text { Total } \\
\text { N (\%) }\end{array}$} & \multicolumn{3}{|c|}{ Statistics } \\
\hline & & & & & $x^{2}$ & $\mathrm{df}$ & $\mathrm{p}$ \\
\hline \multirow{6}{*}{ Age (years) } & $<20$ & $4(1.3)$ & $2(0.7)$ & $6(1.0)$ & 301.388 & 5 & $<0.001$ \\
\hline & $20-29$ & $67(22.3)$ & $0(0.0)$ & $67(11.2)$ & & & \\
\hline & $30-39$ & $111(37.0)$ & $0(0.0)$ & $111(18.5)$ & & & \\
\hline & $40-49$ & $63(21.0)$ & 59 (19.7) & $122\left(\begin{array}{ll}2 & 0.3)\end{array}\right.$ & & & \\
\hline & $50-59$ & $39(13.0)$ & 107 (35.7) & $146(24.3)$ & & & \\
\hline & $\geq 60$ & $16(5.3)$ & $132(44.0)$ & $148(24.7)$ & & & \\
\hline \multirow{2}{*}{ Gender } & Male & $173(55.7)$ & $140(44.7)$ & $313(52.2)$ & 7.274 & 1 & 0.004 \\
\hline & Female & $127(44.3)$ & $160(55.3)$ & $287(47.8)$ & & & \\
\hline \multirow{4}{*}{ Living status } & Alone & $10(3.3)$ & $18(6.0)$ & $28(4.7)$ & 77.763 & 3 & $<0.001$ \\
\hline & Parents/relative & $217(72.3)$ & 119 (39.7) & $336(56.0)$ & & & \\
\hline & Spouse & $65(21.7)$ & $162(54.0)$ & 227 (37.8) & & & \\
\hline & Others & $8(2.7)$ & $1(0.3)$ & $9(1.5)$ & & & \\
\hline \multirow{4}{*}{ Education } & No formal & $12(4.0)$ & $57(19.0)$ & $69(11.5)$ & 40.883 & 3 & $<0.001$ \\
\hline & Primary & $11(3.7)$ & $20(6.7)$ & $31(5.2)$ & & & \\
\hline & Secondary & $132(44.0)$ & $124(41.3)$ & $256(42.7)$ & & & \\
\hline & Tertiary & $145(48.3)$ & $99(33.0)$ & $244(40.7)$ & & & \\
\hline \multirow{4}{*}{ Marital status } & Never married & $155(51.7)$ & $6(2.0)$ & $161(26.8)$ & 245.199 & 3 & $<0.001$ \\
\hline & Married & $90(30.0)$ & $217(72.3)$ & 307 (51.2) & & & \\
\hline & Previously married & $45(15.0)$ & $14(4.7)$ & $59(9.8)$ & & & \\
\hline & Widowed & $10(3.3)$ & $63(21.0)$ & $73(12.2)$ & & & \\
\hline \multirow{3}{*}{ Occupation } & Professionals & $14(4.7)$ & $56(18.7)$ & $70(11.7)$ & 30.965 & 2 & $<0.001$ \\
\hline & Non-professionals & $112(37.3)$ & $112(37.3)$ & $224(37.3)$ & & & \\
\hline & Unemployed & $174(58.0)$ & $132(44.0)$ & $306(51.0)$ & & & \\
\hline \multirow{4}{*}{ Stable Income } & No income & $169(57.3)$ & $97(32.3)$ & $266(44.3)$ & 56.446 & 3 & $<0.001$ \\
\hline & $\mathrm{N}<20,000.00$ & $77(25.7)$ & $79(26.3)$ & $156(26.0)$ & & & \\
\hline & N 20,000 - 49,000 & $49(16.3)$ & $83(27.7)$ & $132(22.0)$ & & & \\
\hline & $\geq 50,000.00$ & $5(1.7)$ & $41(13.7)$ & $46(7.7)$ & & & \\
\hline \multirow{3}{*}{$\begin{array}{l}\text { Duration of } \\
\text { illness (years) }\end{array}$} & $<5$ & $69(23.0)$ & $48(16.0)$ & $117(19.5)$ & 6.684 & 2 & 0.035 \\
\hline & $5-9$ & $97(32.3)$ & $122(40.7)$ & $219(36.5)$ & & & \\
\hline & $\geq 10$ & $134(44.7)$ & $130(43.3)$ & $264(44.0)$ & & & \\
\hline \multirow{2}{*}{$\begin{array}{l}\text { Treatment } \\
\text { adherence }\end{array}$} & Yes & $180(60.0)$ & $239(79.7)$ & $419(69.8)$ & 27.540 & 1 & $<0.001$ \\
\hline & No & $120(40.0)$ & $61(20.0)$ & $181(30.2)$ & & & \\
\hline
\end{tabular}


have a high level of disability, X2 $=10.373, \mathrm{p}<0.001$ (Table 2).

\subsection{Mean WHODAS Scores of Participants with Schizophrenia and Type2DM}

The table shows that the mean WHODAS scores for respondents with Schizophrenia were higher than those with Type2DM in all the Domains $(\mathrm{p}<0.001)$ except Domain 2 with $\mathrm{P}=0.372$. The details of the responses are in Table 3 .

\subsection{Socio-Demographic and Clinical Factors Associated with Disability among Participants with Schizophrenia}

The association between the level of disability and the following socio-demographic factors were statistically significant: living condition, $X^{2}(3, N=$ $300)=10.254, \mathrm{p}=0.017$, marital status, $\mathrm{X}^{2}(3, \mathrm{~N}=300)=9.402, \mathrm{p}=0.024$, and occupation, $\mathrm{X}^{2}(2, \mathrm{~N}=300)=7.537, \mathrm{p}=0.023$, adherence to medications, $\mathrm{X}^{2}(1$, $\mathrm{N}=300)=20.488, \mathrm{p} \leq 0.001$. There was no statistically significant association between level of disability and other socio-demographic variables. The details of the responses are in Table 4.

Table 2. Comparison of levels of disability among participants with schizophrenia and Type2DM based on WHODAS 2.0 disability summary score.

\begin{tabular}{|c|c|c|c|c|c|c|c|}
\hline \multirow{2}{*}{$\begin{array}{c}\text { WHODAS } 2.0 \\
\text { Score }\end{array}$} & \multirow{2}{*}{$\begin{array}{c}\text { Level of } \\
\text { Disability }\end{array}$} & \multirow{2}{*}{ Schizophrenia } & \multirow{2}{*}{ Type2DM } & \multirow{2}{*}{ Total } & \multicolumn{2}{|c|}{ Statistics } & \multirow[b]{2}{*}{$\mathrm{p}$} \\
\hline & & & & & $x^{2}$ & $\mathrm{df}$ & \\
\hline$\geq 10$ & High & $147(57.6)$ & $108(42.4)$ & $255(100.0)$ & 10.373 & 1 & $<0.001$ \\
\hline $0-9$ & Low & $153(44.3)$ & $192(55.7)$ & $345(100.0)$ & & & \\
\hline Mean score & & $21.74 \pm 8.756$ & $9.87 \pm 4.649$ & $15.81 \pm 9.183$ & $\mathrm{t}=20.732$ & & $<0.001$ \\
\hline
\end{tabular}

Table 3. Comparison of the mean WHODAS scores of the participants with schizophrenia and Type2DM across all the domains of disability.

\begin{tabular}{ccccc}
\hline Domains & Schizophrenia & Type2DM & t-test & p \\
\hline Mean score & $21.74 \pm 8.756$ & $9.87 \pm 4.649$ & -20.732 & $<0.001$ \\
D1 & $2.33 \pm 1.922$ & $0.66 \pm 0.770$ & -13.997 & 0.372 \\
D2 & $0.79 \pm 1.222$ & $0.87 \pm 1.155$ & 0.893 & 0.017 \\
D3 & $0.53 \pm 0.790$ & $0.39 \pm 0.677$ & -2.385 & $<0.001$ \\
D4 & $2.58 \pm 2.314$ & $0.4 \pm 0.749$ & -15.572 & -17.534 \\
D5 & $4.78 \pm 3.029$ & $1.24 \pm 1.747$ & -18.691 & $<0.001$ \\
D6 & $10.64 \pm 3.454$ & $6.35 \pm 1.968$ & $<0.001$
\end{tabular}

Key: D1-Understanding and communication; D2-Getting around; D3-Self-care; D4-Getting along; D5-Life activities; D6-Participation in society. 
Table 4. Socio-demographic factors associated with levels of disability among participants with schizophrenia.

\begin{tabular}{|c|c|c|c|c|c|c|c|}
\hline \multirow[b]{2}{*}{ Variables } & & \multicolumn{3}{|c|}{ Type of disability } & \multicolumn{3}{|c|}{ Statistics } \\
\hline & & $\begin{array}{l}\text { Low } \\
\mathrm{n}(\%)\end{array}$ & $\begin{array}{l}\text { High } \\
\text { n (\%) }\end{array}$ & Total N (\%) & $x^{2}$ & Df & $\mathrm{P}$ \\
\hline \multirow{6}{*}{ Age (years) } & $<20$ & $1(0.7)$ & $3(2.0)$ & $4(1.3)$ & 6.562 & 5 & 0.255 \\
\hline & $20-29$ & $38(24.8)$ & $29(19.7)$ & $67(22.3)$ & & & \\
\hline & $30-39$ & $53(34.6)$ & $58(39.5)$ & $111(37.0)$ & & & \\
\hline & $40-49$ & $30(19.6)$ & $33(22.4)$ & $63(21.0)$ & & & \\
\hline & $50-59$ & $25(16.3)$ & $14(9.5)$ & $39(13.0)$ & & & \\
\hline & $\geq 60$ & $6(3.9)$ & $10(6.8)$ & $16(5.3)$ & & & \\
\hline \multirow{2}{*}{ Gender } & Male & $87(56.9)$ & $86(58.5)$ & $173(57.7)$ & 0.083 & 1 & 0.774 \\
\hline & Female & $66(43.1)$ & $61(41.5)$ & $127(42.3)$ & & & \\
\hline Living & Alone & $4(2.6)$ & $6(4.1)$ & $10(3.3)$ & 10.254 & 3 & 0.017 \\
\hline \multirow{3}{*}{ Status } & Parents/relative & $100(65.4)$ & $117(79.6)$ & $217(72.3)$ & & & \\
\hline & Spouse & $44(28.8)$ & $21(14.3)$ & $65(21.7)$ & & & \\
\hline & Others & $5(3.3)$ & $3(2.0)$ & $8(2.7)$ & & & \\
\hline \multirow{4}{*}{ Education } & No formal & $3(2.0)$ & $9(6.1)$ & $12(4.0)$ & 4.259 & 3 & 0.235 \\
\hline & Primary & $7(4.6)$ & $4(2.7)$ & $11(3.7)$ & & & \\
\hline & Secondary & $66(43.1)$ & $66(44.9)$ & $132(44.0)$ & & & \\
\hline & Tertiary & $77(50.3)$ & $68(46.3)$ & $145(48.3)$ & & & \\
\hline \multirow{4}{*}{ Marital status } & Never married & $70(45.8)$ & $85(57.8)$ & $155(51.7)$ & 9.402 & 3 & 0.024 \\
\hline & Married & $58(37.9)$ & $32(21.8)$ & $90(30.0)$ & & & \\
\hline & Previously married & $20(13.1)$ & $25(17.0)$ & $45(15.0)$ & & & \\
\hline & Widowed & $5(3.3)$ & $5(3.4)$ & $10(3.3)$ & & & \\
\hline \multirow{3}{*}{ Occupation } & Professionals & $12(7.8)$ & $2(1.4)$ & $14(4.7)$ & 7.537 & 2 & 0.023 \\
\hline & Non-professionals & $58(37.9)$ & $54(36.7)$ & $112(37.3)$ & & & \\
\hline & Unemployed & $83(54.2)$ & $91(61.9)$ & $174(58.0)$ & & & \\
\hline \multirow{4}{*}{ Stable Income } & No income & $80(52.3)$ & $89(60.5)$ & $169(56.3)$ & 2.776 & 3 & 0.428 \\
\hline & $\mathrm{N}<20,000.00$ & $45(29.4)$ & $32(21.8)$ & $77(25.7)$ & & & \\
\hline & N $20-49,000.00$ & $25(16.3)$ & $24(16.3)$ & $49(16.3)$ & & & \\
\hline & $\geq 50,000.00$ & $3(2.0)$ & $2(1.4)$ & $5(1.7)$ & & & \\
\hline \multirow{3}{*}{$\begin{array}{l}\text { Duration of illness } \\
\text { (years) }\end{array}$} & $<5$ & $43(28.1)$ & $27(18.4)$ & $70(23.3)$ & 4.626 & 2 & 0.099 \\
\hline & $5-9$ & $47(30.7)$ & $45(30.6)$ & $92(30.7)$ & & & \\
\hline & $\geq 10$ & $63(41.2)$ & $75(51.0)$ & $138(46.0)$ & & & \\
\hline \multirow{2}{*}{ Treatment adherence } & Yes & $111(72.5)$ & $69(46.9)$ & $180(60.0)$ & 20.488 & 1 & $<0.001$ \\
\hline & No & $42(27.5)$ & $78(53.1)$ & $120(40.0)$ & & & \\
\hline
\end{tabular}




\subsection{Socio-Demographic and Clinical Factors Associated with Disability among Participants with T2DM}

Comparison of the level of disability among participants with Type2DM reveals a statistically significant association between the level of disability and the following socio-demographic factors: age, $\mathrm{X} 2(3, \mathrm{~N}=300)=12.785, \mathrm{p}=0.005$, living condition, $\mathrm{X} 2(3, \mathrm{~N}=300)=9.171, \mathrm{p}=0.027$, marital status, $\mathrm{X} 2(3, \mathrm{~N}=300)=$ 13.077, $\mathrm{p}=0.004$, and occupation, $\mathrm{X} 2(2, \mathrm{~N}=300)=23.487, \mathrm{p}<0.001$, income, $\mathrm{X} 2(3, \mathrm{~N}=300)=18.472, \mathrm{p}<0.001$, duration of illness, $\mathrm{X} 2(2, \mathrm{~N}=300)=22.709$, $\mathrm{p} \leq 0.001$ adherence to medications, $\mathrm{X} 2(1, \mathrm{~N}=300)=22.978, \mathrm{p} \leq 0.001$ There was no statistically significant association between level of disability and other socio-demographic variables. The details are presented in Table 5.

Table 5. Socio-demographic factors associated with levels of disability among participants with T2DM.

\begin{tabular}{|c|c|c|c|c|c|c|c|}
\hline \multirow{2}{*}{ Variables } & & \multicolumn{2}{|c|}{ Disability Type } & \multirow[b]{2}{*}{ Total N (\%) } & \multicolumn{3}{|c|}{ Statistics } \\
\hline & & Low n (\%) & High n (\%) & & $x^{2}$ & Df & $\mathrm{P}$ \\
\hline \multirow{6}{*}{ Age(years) } & $<20$ & $2(1.0)$ & $0(0.0)$ & $2(0.7)$ & 12.785 & 3 & 0.005 \\
\hline & $20-29$ & $0(0.0)$ & $0(0.0)$ & $0(0.0)$ & & & \\
\hline & $30-39$ & $0(0.0)$ & $0(0.0)$ & $0(0.0)$ & & & \\
\hline & $40-49$ & $47(24.5)$ & $12(11.1)$ & $59(19.7)$ & & & \\
\hline & $50-59$ & $71(37.0)$ & $36(33.3)$ & $107(35.7)$ & & & \\
\hline & $\geq 60$ & $72(37.5)$ & $60(55.6)$ & $132(44.0)$ & & & \\
\hline \multirow{2}{*}{ Gender } & Male & $88(45.8)$ & $52(48.1)$ & $140(46.7)$ & 0.149 & 1 & 0.700 \\
\hline & Female & $104(54.2)$ & $56(51.9)$ & $160(53.3)$ & & & \\
\hline \multirow{3}{*}{ Residential } & Urban & $130(67.7)$ & $69(63.9)$ & $199(66.3)$ & 2.223 & 2 & 0.329 \\
\hline & Semi-urban & $50(26.0)$ & $27(25.0)$ & $77(25.7)$ & & & \\
\hline & Rural & $12(6.3)$ & $12(11.1)$ & $24(8.0)$ & & & \\
\hline \multirow{4}{*}{ Living status } & Alone & $9(4.7)$ & $9(8.3)$ & $18(6.0)$ & 9.171 & 3 & 0.027 \\
\hline & Parents/relative & $68(35.4)$ & $51(47.2)$ & $119(39.7)$ & & & \\
\hline & Spouse & $115(59.9)$ & $47(43.5)$ & $160(54.0)$ & & & \\
\hline & Others & $0(0.0)$ & $1(0.9)$ & $1(0.3)$ & & & \\
\hline \multirow{4}{*}{ Education } & No formal & $34(17.7)$ & $23(21.3)$ & $57(19.0)$ & 18.994 & 3 & $<0.001$ \\
\hline & Primary & $12(6.3)$ & $8(7.4)$ & $20(6.7)$ & & & \\
\hline & Secondary & $66(34.4)$ & $58(53.7)$ & $124(41.3)$ & & & \\
\hline & Tertiary & $80(41.7)$ & $19(17.6)$ & $99(33.3)$ & & & \\
\hline \multirow{4}{*}{ Marital status } & Never married & $5(2.6)$ & $1(0.9)$ & $6(2.0)$ & 13.077 & 3 & 0.004 \\
\hline & Married & $150(78.1)$ & $67(62.0)$ & $217(72.3)$ & & & \\
\hline & Previously married & $5(2.6)$ & $9(8.3)$ & $14(4.7)$ & & & \\
\hline & Widowed & $32(16.7)$ & $31(28.7)$ & $63(21.0)$ & & & \\
\hline \multirow{3}{*}{ Occupation } & Professionals & $50(26.0)$ & $6(5.6)$ & $56(18.7)$ & 23.487 & 2 & $<0.001$ \\
\hline & Non-professionals & $73(38.0)$ & $39(36.1)$ & $112(37.3)$ & & & \\
\hline & Unemployed & $69(35.9)$ & $63(58.3)$ & $132(44.0)$ & & & \\
\hline
\end{tabular}




\begin{tabular}{|c|c|c|c|c|c|c|c|}
\hline \multirow{4}{*}{ Stable Income } & No income & $47(24.5)$ & $50(46.3)$ & $97(32.3)$ & \multirow[t]{4}{*}{18.472} & \multirow[t]{4}{*}{3} & \multirow[t]{4}{*}{$<0.001$} \\
\hline & $\mathrm{N}<20,000.00$ & $52(27.1)$ & $27(25.0)$ & $79(26.3)$ & & & \\
\hline & N 20,000 - 49,000.00 & $59(30.7)$ & $24(22.2)$ & $83(27.7)$ & & & \\
\hline & $\geq 50,000.00$ & $34(17.7)$ & $7(6.5)$ & $41(13.7)$ & & & \\
\hline \multirow{4}{*}{$\begin{array}{l}\text { Duration of illness } \\
\text { (years) }\end{array}$} & $<5$ & $44(22.9)$ & $4(3.7)$ & $48(16.0)$ & \multirow[t]{4}{*}{22.709} & \multirow[t]{4}{*}{2} & \multirow[t]{4}{*}{$<0.001$} \\
\hline & & & & & & & \\
\hline & $5-9$ & $79(41.1)$ & $43(39.8)$ & $122(40.7)$ & & & \\
\hline & $\geq 10$ & $69(35.9)$ & $61(56.5)$ & $130(43.3)$ & & & \\
\hline \multirow{2}{*}{$\begin{array}{l}\text { Treatment } \\
\text { adherence }\end{array}$} & Yes & $169(88.0)$ & $70(64.8)$ & $239(79.7)$ & \multirow[t]{2}{*}{22.978} & \multirow[t]{2}{*}{1} & \multirow[t]{2}{*}{$<0.001$} \\
\hline & No & $23(12.0)$ & $38(35.2)$ & $61(20.3)$ & & & \\
\hline
\end{tabular}

\section{Discussion}

The vast majority of patients with chronic conditions experience a functional disability. The degree/levels of disability correlate with the type and severity of the disorders experienced by individuals [5] [6]. Our study compared disability levels among individuals with Schizophrenia and T2DM based on the WHODAS score. We collected data from adults visiting the psychiatric and medical outpatient clinics of the Jos University Teaching Hospital. The total investigated adults were 600 , with 300 from psychiatric and medical outpatient clinics, respectively. Patients with schizophrenia and T2DM varied significantly in all the sociodemographic and clinical characteristics measured.

Disability occurred in all respondents. However, persons with schizophrenia reported a higher level of disability than did those with T2DM on the disability summary score and on each disability domain of the WHODAS 2.0, except getting around.

Studies that specifically compare disability levels among persons with schizophrenia and T2DM are not readily available. However, in their respective studies, Ormel et al., 2013 [5]; Benjamin et al., 2006 [7]; Suliman et al., 2010 [38]; and Buis-Bouwman et al., 2006 [39] found participants with other mental disorders to be more disabling than those with physical disorders. And, studies that compared disability among mental disorders revealed that schizophrenia was consistently more disabling than other mental disorders surveyed [6] [34] [40]. Furthermore, in the National Comorbidity Survey Replication in the United States, Benjamin et al., 2006 [7] indicated that chronic medical conditions are likely to impair the physical performance, limiting home and work functioning; mental disorders impede social functioning and relationships. In terms of onset of disability, De Jong et al. (1985) [41] reported that disability in schizophrenia starts primarily in social role, occupational functioning, and interpersonal relationship, which are closely related to the domains of getting along, Life activities, and participation in society, which often contribute to the greatest severity of a 
global disability. In contrast, T2DM usually develops into complications, leading to functional impairments in performing a physical task, which is closely related to the domains getting around [17] [18] [19] [20]. In support of this, our results show that the WHODAS scores for respondents with schizophrenia were significantly higher than those with Type2DM in all the Domains except the domain getting around.

Another plausible explanation for the higher level of disability found among respondents with schizophrenia than those with T2DM might have been the beliefs about the aetiology of a disease condition. Most cultures in Nigeria attribute mental illnesses rather than physical conditions to supernatural causation [42] [43] [44]. This belief implies an increased likelihood of accessing care from spiritual or traditional healers, resulting in a delay in presenting to a mental health care facility. This delay eventually leads to a longer duration of untreated psychosis, which constitutes an active morbid process, with brain damage, leading to poor outcomes and, consequently, an increased level of disability [45]. A study by Aghukwa [43] in northern Nigeria revealed that about $70 \%$ of respondents who endorsed supernatural attributions to mental illnesses sought help from mental health professionals five years or later after the onset of the disease.

Among the respondents with schizophrenia, marital status, living situation, occupation, and treatment adherence were the significant sociodemographic and clinical characteristics associated with disability.

Specifically, a high level of disability occurred among those who were unmarried as compared with those respondents who were married, which is similar to other studies conducted in Nigeria [35] [46] and Zambia [47], but in contrast to some studies that found no association between marital status and functional disability [48] [49] [50]. Being unmarried or living alone complicates schizophrenia by decreasing social support and non-adherence to treatment, leading to multiple relapses and poor functional outcomes and quality of life.

Furthermore, persons with schizophrenia often experience discrimination that limits their opportunities to enter and form lasting partnerships or live with other people [51].

Concerning occupation, our results showed that being unemployed was strongly associated with a high level of disability compared to being employed, supported by a study conducted in Taiwan [52]. In schizophrenia, life activities, participation in society, understanding and communication, and getting along with people, which constitute skills needed for a productive life, seem to be the domains where disability levels are more apparent [14] [41].

The results also show that poor treatment adherence was associated with a high level of disability, which is in keeping with previous studies conducted in Nigeria [53], and elsewhere [54] [55]. In schizophrenia, the relationship between treatment adherence and disability could be bidirectional. While individuals who do not adhere to treatment won't sustain significant clinical improvement, resulting in high levels of disability [48], those with high levels of disability will 
be less stable mentally; and, consequently, adhere less to treatment. Studies have shown that disability can be minimized or avoided in people with chronic conditions who adhere to treatment [8] [9] [10]. Unfortunately, treatment adherence is far from reality in developing countries, including Nigeria and, indeed, our study population. It is often due to poor insight and belief in the supernatural causation of mental illness, financial constraints, and side effects of antipsychotics, especially the older generation antipsychotics prescribed because of their affordability.

Among the respondents with T2DM, we found a significant association between disability and all the sociodemographic and clinical factors evaluated. Thus, disability was significantly associated with age, with respondents who were 60 years and above constituting more than half of those with high levels of disability. This finding is similar to previous studies that reported high levels of disability among older adults with diabetes [56] [57] [58]. Aging and diabetes are conditions that simultaneously increase the risk of disabling conditions such as loss of muscle mass, hearing/visual impairments, peripheral vascular disease, and peripheral neuropathy [17] [18] [19] [20].

We found a higher level of disability among the unmarried and those living alone than those married. Previous studies conducted in Nigeria [59], Ethiopia [60], the USA [61], and Brazil [62] reported the same. A plausible interpretation of our results might hold that the effects of being unmarried or living alone are indicative of decreased social support and treatment adherence, especially among older people who may be experiencing sarcopenia (natural loss of muscle mass) with reduced mobility and cognitive decline to the extent that they often forget to take their oral hypoglycemics regularly. Over time, hyperglycaemia could initiate a part of a multifactorial process, eventually resulting in disability. More so, about $80 \%$ of our respondents with T2DM were 50 years and above.

In this study, indicators of low socioeconomic status such as low level of education, unemployment and, having little or no stable income were apparent among respondents with a high level of disability. Studies conducted in the UK [63] and the USA [64] reported the same. Unfortunately, diabetes is a chronic condition with a high cost of treatment. Unfortunately, our environment's economic fortune is low, and the health insurance scheme is limited to few people. A significant implication is an increased likelihood of non-adherence to treatment, resulting in difficulty controlling hyperglycaemia, which constitutes a part of a morbid process, eventually leading to disability [65] [66]. On the other hand, persons with disabilities are more likely to experience adverse socioeconomic outcomes such as low education, lower employment level, higher poverty rates, and poorer health outcomes [3] [4].

The study also revealed a higher level of disability among respondents who have had diabetes for 10 - 15 years. This finding is in tandem with the results of previous studies, which suggested that the longer the duration of diabetes, the greater the risk of disability [67]. For instance, a physical disability could result 
from rapid loss of skeletal muscle strength and quality, worsening with increased duration of diabetes [68] [69].

Strength: This is the first study to compare disability levels between patients with schizophrenia and T2DM in north-central Nigeria. The fact that the results were broadly consistent with previous research supports the validity of our findings.

Additionally, we employed a scientifically sound methodology to recruit our study participants using validated instruments, BPRS, to assess Psychotic and non-psychotic symptoms among those with Schizophrenia and WHODAS to measure disability. Our findings were similar to other previous studies.

We also have some limitations: We could not demonstrate the temporal link between the disability and the chronic conditions studied as a cross-sectional study.

The cross-sectional design lacks an objective measurement to reveal all details about a respondent. Therefore, responses are subject to manipulations by respondents.

A further limitation is that these results cannot be generalized all over north-central Nigeria as it was a hospital-based study, limited to a particular hospital. At the same time, a substantial number of people living with these chronic conditions abound in the community.

\section{Conclusion}

This study showed that though disability occurred in both schizophrenia and T2DM, people with schizophrenia had a higher level of disability than those with T2DM. The results also highlight the significant factors associated with both conditions. Thus, functional disability and its associated factors, if identified and treated early, can be minimized or avoided in people with chronic illnesses.

\section{Acknowledgements}

We want to thank the heads of departments, Psychiatry and Internal Medicine, for permitting us to conduct this research in their departments. Our profound gratitude goes to the participants for cooperating with us during the interviews.

\section{Conflicts of Interest}

The authors declare no conflicts of interest.

\section{References}

[1] Wikipedia. Chronic Condition. https://en.wikipedia.org/wiki/Chroniccondition

[2] World Health Organization (1988) Psychiatric Disability Assessment Schedule (WHODAS). World Health Organization, Geneva.

[3] World Health Organization (2020) Report on Disability and Health.

[4] A Statement from the World Bank Group on the Occasion of the UN High-Level Meeting of the General Assembly on Disability and Development (HLMDD): New 
York, September 23, 2013.

[5] Ormel, J., Petukhova, M., Chatterji S., Aguilar-Gaxiola, S., Alonso, J., Matthias, C., et al. (2008) Disability and Treatment of Specific Mental and Physical Disorders across the World: Results from the WHO World Mental Health Surveys. The British Journal of Psychiatry, 5, 368-375. https://doi.org/10.1192/bjp.bp.107.039107

[6] Pranit, K.C., Kamala, D. and Dhrubajyoti, C. (2006) Disability Associated with Mental Disorders. Indian Journal of Psychiatry, 48, 95-101.

https://doi.org/10.4103/0019-5545.31597

[7] Druss, B.G., Hwang, I., Petukhova, M., Sampson, N.A., Wang, P.S. and Kessler, R.C. (2009) Impairment in Role Functioning in Mental and Chronic Medical Disorders in the United States: Results from the National Comorbidity Survey Replication. Molecular Psychiatry, 14, 728-737. https://doi.org/10.1038/mp.2008.13

[8] Thirthalli, J., Venkatesh, B.K., Kishorekumar, K.V., et al. (2009) Prospective Comparison of Course of Disability in Antipsychotic-Treated and Untreated Schizophrenia Patients. Acta Psychiatrica Scandinavica, 119, 209-217. https://doi.org/10.1111/j.1600-0447.2008.01299.x

[9] Thirthalli, J., Venkatesh, B.K., Naveen, M.N., et al. (2006) Do Antipsychotics Limit Disability in Schizophrenia? A Naturalistic Comparative Study in the Community. Indian Journal of Psychological Medicine, 28, 14-19. https://doi.org/10.1177/0975156420060205

[10] Lo-Ciganic, W.H., Donohue, J.M., Jones, B.L., Perera, S., Thorpe, J.M., Thorpe, C.T., et al. (2016) Trajectories of Diabetes Medication Adherence and Hospitalization Risk: A Retrospective Cohort Study in a Large State Medicaid Program. Journal of General Internal Medicine, 31, 1052-1060.

https://doi.org/10.1007/s11606-016-3747-6

[11] Thara, R. and Menon, M.S. (1991) A New Perspective of Disability-Chronic Mental Illness. Indian Journal of Disability and Rehabilitation, 5, 33-36.

[12] Mohan, I., Tandon, R., Kalra, H. and Trivedi, J.K. (2005) Disability Assessment in Mental Illnesses Using Indian Disability Evaluation Assessment Scale (IDEAS). Indian Journal of Medical Research, 121, 759-763.

[13] Vos, T., Abajobir, A.A., Abate, K.H., et al. (2017) Global, Regional, and National Incidence, Prevalence, and Years Lived with Disability for 328 Diseases and Injuries for 195 Countries, 1990-2016: A Systematic Analysis for the Global Burden of Disease Study. The Lancet, 390, 1211-1259. https://doi.org/10.1016/S0140-6736(17)32154-2

[14] Ertugrul, A. and Ulug, B. (2002) The Influence of Neurocognitive Deficits and Symptoms on Disability in Schizophrenia. Acta Psychiatrica Scandinavica, 105, 196-201. https://doi.org/10.1034/j.1600-0447.2002.1020.x

[15] American Diabetes Association (2013) Standards of Medical Care in Diabetes. Diabetes Care, 36, 11-66. https://doi.org/10.2337/dc13-S011

[16] Kotwas, A., Karakiewicz, B., Zabielska, P., et al. (2021) Epidemiological Factors for Type 2 Diabetes Mellitus: Evidence from the Global Burden of Disease. Archives of Public Health, 79, 110. https://doi.org/10.1186/s13690-021-00632-1

[17] Gregg, E.W., Cheng, Y.J., Saydah, S., Cowie, C., Garfield, S., Geiss, L. and Barker, L. (2012) Trends in Death Rates among U.S. Adults with and without Diabetes between 1997 and 2006: Findings from the National Health Interview Survey. Diabetes Care, 35, 1252-1257. https://doi.org/10.2337/dc11-1162

[18] Caspersen, C.J., Thomas, G.D., Boseman, L.A., Beckles, G.L. and Albright, A.L. 
(2012) Aging, Diabetes, and the Public Health System in the United States. American Journal of Public Health, 102, 1482-1497. https://doi.org/10.2105/AJPH.2011.300616

[19] Phelan, E.A., Anderson, L.A., LaCroix, A.Z. and Larson, E.B. (2004) Older Adults' Views of "Successful Aging": How Do They Compare with Researchers' Definitions? Journal of the American Geriatrics Society, 52, 211-216. https://doi.org/10.1111/j.1532-5415.2004.52056.x

[20] Lawton, M.P. and Brody, E.M. (1969) Assessment of Older People: Self-Maintaining and Instrumental Activities of Daily Living. Gerontologist, 9, 179-186. https://doi.org/10.1093/geront/9.3 Part 1.179

[21] Rodbard, H.W., Fox, K.M. and Grandy, S. (2009) Impact of Obesity on Work Productivity and Role Disability in Individuals with and at Risk for Diabetes Mellitus. The American Journal of Health Promotion, 23, 353-360. https://doi.org/10.4278/ajhp.081010-QUAN-243

[22] Gregg, E.W., Beckles, G.L., Williamson, D.F., et al. (2000) Diabetes and Physical Disability among Older U.S. Adults. Diabetes Care, 23, 1272-1277. https://doi.org/10.2337/diacare.23.9.1272

[23] Bourdel-Marchasson, I., Helmer, C., Fagot-Campagna, A., Dehail, P. and Joseph, P.A. (2007) Disability and Quality of Life in Elderly People with Diabetes. Diabetes Metabolism, 33, 66-74. https://doi.org/10.1016/S1262-3636(07)80058-9

[24] World Health Organization (1992) International Classification of Disease and Related Health Problem. Tenth Edition, World Health Organization, Geneva.

[25] World Health Organisation (WHO) (1999) Definition, Diagnosis, and Classification of Diabetes Mellitus and Its Complications. World Health Organisation, Geneva.

[26] Fleiss, J.L. (1981) Statistical Methods for Rates and Proportions. 2nd Edition, Wiley, New York, 17.

[27] Liu, X., Zhang, L., Pang, L., Li, N., Chen, G. and Zheng, X. (2015) Schizophrenia-Related Disability in China: Prevalence, Gender, and Geographical Location. Psychiatry Service, 66, 249-257. https://doi.org/10.1176/appi.ps.201400032

[28] National Health Surveys 1997-2011.

[29] Lukoff, D., Nuechterlien, K. and Ventura, J. (1986) The Brief Psychiatric Rating Scale Manual for the Expanded Version. Schizophrenia Bulletin, 13, 261-276.

[30] Ohaeri, J.U. and Otote, D.I. (2003) Subtypes and Factors of Schizophrenia in an Acutely Ill Nigeria Sample. Psychopathology, 36, 181-189.

https://doi.org/10.1159/000072787

[31] Adewuya, A.O., Owoeye, A.O., Ola, B.A. and Erinfolami, A.O. (2011) Correlates of Self-Stigma among Outpatients with Mental Illness in Lagos, Nigeria. International Journal of Social Psychiatry, 57, 418-427. https://doi.org/10.1177/0020764010363522

[32] Uwakwe, R. and Modebe, I. (2007) Disability and Care-Giving in Old Age in a Nigerian Community. Nigerian Journal of Clinical Practice, 10, 58-65.

[33] Frick, N., Rehm, J. and Chatterji, S. (2000) Psychometric Properties of the World Health Organization Disability Assessment Schedule (WHODAS 2.0). American Journal of Physical Medicine and Rehabilitation, 72, 84-89.

[34] Adebagbaju, D., Olagunju, A. and Uwakwe, R. (2013) A Comparative Analysis of Disability in Individuals with Bipolar Affective Disorder and Schizophrenia in a Sub-Saharan African Mental Health Hospital: Towards Evidence Guided Rehabilitation Intervention. Social Psychiatry and Psychiatric Epidemiology, 48, 1405-1415. 
https://doi.org/10.1007/s00127-013-0654-6

[35] Akinsulore, A., Mapayi, B.M., Aloba, O.O., Oloninyi, I., Fatoye, F.O. and Makanjuola, R.O. (2015) Disability Assessment as an Outcome Measure: A Comparative Study of Nigerian Outpatients with Schizophrenia and Healthy Controls. Annals of General Psychiatry, 14, 40-43. https://doi.org/10.1186/s12991-015-0079-6

[36] Andrews, G., Kemp, A., Sunderland, M., Von Korff, M. and Ustun, T.B. (2009) Normative Data for the 12 Item WHO Disability Assessment Schedule 2.0. PLoS ONE, 4, e8343. https://doi.org/10.1371/journal.pone.0008343

[37] Taru, M.Y., Audu, M.D., Philip, T.F., John, D.F., Yushau, A.A., Nnaemeka, C.N. and Bamidele, L.I. (2018) Armed Conflict and Depression among Heads of Households in Dogonahawa, North-Central Nigeria: Prevalence and Correlates. Open Journal of Depression, 7, 17-30. https://doi.org/10.4236/ojd.2018.72002

[38] Suliman, S., Stein, D., Myer, L., Williams, D. and Seedat, S. (2010) Disability and Treatment of Psychiatric and Physical Disorders in South Africa. The Journal of Nervous and Mental Diseases, 198, 8-15.

https://doi.org/10.1097/NMD.0b013e3181c81708

[39] Buist-Bouwman, M., De Graaf, R., Vollebergh, W., Bruffaerts, R. and Alonso, J. (2006) Functional Disability of Mental Disorders and Comparison with Physical Disorders: A Study among the General Population of Six European Countries. Acta Psychiatrica Scandinavica, 113, 492-500. https://doi.org/10.1111/j.1600-0447.2005.00684.x

[40] Johnson, S., Sathyaseelan, M., Charles, H., Jeyaseelan, V. and Jacob, K.S. (2012) Insight, Psychopathology, Explanatory Models and Outcome of Schizophrenia. A Prospective 5-Year Cohort Study. BMC Psychiatry, 12, Article No. 159. https://doi.org/10.1186/1471-244X-12-159

[41] De Jong, A., Giel, R., Slooff, C.J. and Wiersma, D. (1985) Social Disability and Outcome in Schizophrenic Patients. British Journal of Psychiatry, 147, 631-636. https://doi.org/10.1192/bjp.147.6.631

[42] Aghukwa, C.N. (2012) Care and Beliefs about the Cause of Mental Illness among Nigerian Patients and Their Families. Psychiatric Services, 12, 59-63. https://doi.org/10.1176/appi.ps.201000343

[43] Adebowale, T.O. and Oguunlesi, A.O. (1999) Beliefs and Knowledge about Aetiology of Mental Illness among Nigerian Psychiatric Patients and Their Relatives. African Journal of Medicine and Medical Sciences, 28, 35-41.

[44] Adewuya, A.O. and Makanjuola, R.O.A. (2008) Lay Beliefs Regarding Causes of Mental Illness in Nigeria: Pattern and Correlates. Social Psychiatry and Psychiatric Epidemiology, 43, 336-341. https://doi.org/10.1007/s00127-007-0305-X

[45] Norman, R.M. and Malla, A.K. (2001) Duration of Untreated Psychosis: A Critical Examination of the Concept and Its Importance. Psychological Medicine, 31, 381-400. https://doi.org/10.1017/S0033291701003488

[46] Campbell, E., Olagunju, A., Aina, O. and Ogbolu, R. (2015) Assessment of Functioning among Nigerians with Schizophrenia in a Tertiary Health Facility: Influence of Psychopathology, Socio-Demographic and Treatment Factors. Journal of Psychosocial Rehabilitation and Mental Health, 2, 35-41.

https://doi.org/10.1007/s40737-015-0025-6

[47] Kapungwe, A., Cooper, S., Mwanza, J., Mwape, L., Sikwese, A., Kakuma, R., Lund, C. and Flisher, A.J. (2010) Mental Illness: Stigma and Discrimination in Zambia. African Journal of Psychiatry, 13, 192-203.

[48] Gupta, A. and Chadda, R.K. (2008). Disability in Schizophrenia: Do Short Hospita- 
lizations Have a Role? International Journal of Psychosocial Rehabilitation, 13, 91-96.

[49] Kebede, D., Alem, A., Shibre, T., Negash, A., Deyassa, N., Beyero, T. and Medhin, G. (2005) Short-Term Symptomatic and Functional Outcomes of Schizophrenia in Butajira, Ethiopia. Schizophrenia Research, 78, 171-185. https://doi.org/10.1016/j.schres.2005.05.028

[50] Kua, J., Wong, K.E., Kua, E.H. and Tsoi, W.F. (2003) A 20-Year Follow-Up Study on Schizophrenia in Singapore. Acta Psychiatrica Scandinavica, 108, 118-125. https://doi.org/10.1034/j.1600-0447.2003.00107.x

[51] Ishaq, A. A., Suleiman, H.I., Victor, O.O. and Taiwo, L.S. (2013) Stigmatization of People with Mental Illness among Inhabitants of a Rural Community in Northern Nigeria. International Journal of Social Psychiatry, 59, 55-60. https://doi.org/10.1177/0020764011423180

[52] Chen, R., Liou, T.H., Chang, K.H., Yen, C.F., Liao, H.F., Chi, W.C., et al. (2018) Assessment of Functioning and Disability in Patients with Schizophrenia Using the WHO Disability Assessment Schedule 2.0 in a Large-Scale Database. European Archives of Psychiatry and Clinical Neuroscience, 268, 65-75.

https://doi.org/10.1007/s00406-017-0834-6

[53] Adefulosi, A.O., Adebowale, T.O., Abayomi, O. and Mosanya, J.T. (2012) Medication Adherence and Quality of Life among Nigerian Outpatients with Schizophrenia. General Hospital Psychiatry, 34, 72-79. https://doi.org/10.1016/j.genhosppsych.2011.09.001

[54] Novick, D., Montgomery, W., Treuer, T., Aguodo, J., et al. (2015) Relationship of Insight with Medication Adherence and the Impact on Outcomes in Patients with Schizophrenia and Bipolar Disorder: Results from a 1-Year European Outpatient Observational Study. BMC Psychiatry, 15, Article No. 189.

https://doi.org/10.1186/s12888-015-0560-4

[55] Kumar, C.N., Thirthalli, J., Yadav, M. and Gangadhar, B.N. (2014) Certifiable Disability in First Episode Schizophrenia. The Role of Adherence to Antipsychotic Treatment. Journal of Psychosocial Rehabilitation and Mental Health, 2, 55-59. https://doi.org/10.1007/s40737-014-0016-Z

[56] World Health Organization (2016) Global Reports on Diabetes. https://apps.who.int/iris/handle/10665/204871 https://doi.org/10.1017/9781316488485

[57] Ojczyńska, A. (2017) Use of Aggregated Parameters of Lack of Health in the Assessment of the Effect of Selected Diseases and Disabilities on the Health Status of Polish Population. Studia Ekonomiczne-Zeszyty Naukowe Uniwersytetu Ekonomicznego w Katowicach, 309, 169-178.

[58] Cheng, Y.J., Imperatore, G., Geiss, L.S., Wang, J., Saydah, S.H., Cowie, C.C. and Gregg, E.W. (2013) Secular Changes in the Age-Specific Prevalence of Diabetes among U.S. Adults: 1988-2010. Diabetes Care, 36, 2690-2696.

https://doi.org/10.2337/dc12-2074

[59] Abdulraheem, I.S., Oladipo, A.R. and Amodu, M.O. (2011) Prevalence and Correlates of Physical Disability and Functional Limitation among Elderly Rural Population in Nigeria. Journal of Aging Research, 2011, Article ID: 369894.

https://doi.org/10.4061/2011/369894

[60] Fitaw, Y. and Boersma, J.M. (2006) Prevalence and Impact of Disability in North-Western Ethiopia. Disability and Rehabilitation, 28, 949-953.

https://doi.org/10.1080/09638280500404552 
[61] Ostchega, Y., Harris, T.B., Hirsch, R., Parsons, V.L. and Kington, R. (2000) The Prevalence of Functional Limitations and Disability in Older Persons in the US: Data from the National Health and Nutrition Examination Survey III. Journal of the American Geriatrics Society, 48, 1132-1135. https://doi.org/10.1111/j.1532-5415.2000.tb04791.x

[62] Melzer, D. and Parahyba, M.I. (2004) Socio-Demographic Correlates of Mobility Disability in Older Brazilians: Results of the First National Survey. Age Ageing, 33, 253-259. https://doi.org/10.1093/ageing/afh075

[63] Braithwaite, J. and Mont, D. (2009) Disability and Poverty: A Survey of World Bank Poverty Assessments and Implications. ALTER-European Journal of Disability Research/Revue Européenne de Recherche sur le Handicap, 3, 219-232. https://doi.org/10.1016/j.alter.2008.10.002

[64] Mayfield, J.A., Deb, P. and White Cotton L. (1999) Work Disability and Diabetes. Diabetes Care, 22, 1105-1109. https://doi.org/10.2337/diacare.22.7.1105

[65] Volpato, C. and Maraldi, R.F. (2010) Type 2 Diabetes and Risk for Functional Decline and Disability in Older Persons. Current Diabetes Reports, 6, 134-143. https://doi.org/10.2174/157339910791162961

[66] Lu, F.-P., Lin, K.-P. and Kuo, H.-K. (2009) Diabetes and the Risk of Multi-System Aging Phenotypes: A Systematic Review and Meta-Analysis. PLoS ONE, 4, e4144. https://doi.org/10.1371/journal.pone.0004144

[67] Wu, J.H., Haan, M.N., Liang, J., Ghosh, D., Gonzalez, H.M. and Herman, W.H. (2003) Diabetes as a Predictor of Change in Functional Status among Older Mexican Americans: A Population-Based Cohort Study. Diabetes Care, 26, 314-319. https://doi.org/10.2337/diacare.26.2.314

[68] Park, S.W., Goodpaster, H.B., Strotmeyer, E.S., et al. (2007) Accelerated Loss of Skeletal Muscle Strength in Older Adults with Type 2 Diabetes: The Health, Aging, and Body Composition Study. Diabetes Care, 30, 1507-1512. https://doi.org/10.2337/dc06-2537

[69] Park, S.W., Goodpaster, H.B., Strotmeyer, E.S., et al. (2006) Decreased Muscle Strength and Quality in Older Adults with Type 2 Diabetes: The Health, Aging, and Body Composition Study. Diabetes, 55, 1813-1818.

https://doi.org/10.2337/db05-1183 